\title{
Prevention and Correction of Immunodeficiency States of Animals, Chemical Etiology
}

Salimov Yu* and Toshmuratov EA

Department of veterinary surgery, pharmacology and toxicology, Uzbekistan

*Corresponding author: Salimov Y, Department of veterinary surgery, pharmacology and toxicology, Uzbekistan

Keywords: A synthetic pyrethroid; Organophosphorus compounds; Xenobiotics immunotoxicity; etapas; Neotomodon; Esfenvalerate

\section{Introduction}

In recent years, in farm and private livestock farms in Uzbekistan there has been a decrease in the resistance of animals and, especially, young animals to various bacterial and viral infections. Often there is a decrease and a complete lack of protective action of known vaccines and serums, which causes serious economic damage to livestock. One of the leading factors of this pathology is the unfavorable ecological situation which has developed in many regions of the Republic owing to various anthropogenic influences, including: application of pesticides and other toxic xenobiotics and also emissions of industrial productions. The use of synthetic pyrethroids and organophosphorus compounds in crop production and veterinary medicine helps to preserve crop yields, reduce production costs and reliably protects farm animals from various infections and invasions. However, irrational use them (overstatement of rules and number of treatment, failure to comply with the "waiting time", violation of regulations of storage and transport) leads to environmental pollution and cause toxicity to humans, animals and other negative effects. Among other toxic substances that have an adverse effect on living organisms and cause such negative effects as immunotoxicity, gonadotoxicity and embryotoxicity, emissions from industrial production, in which fluorine compounds are detected, deserve special attention.

\section{Annotation}

Results on prevention and correction of immunodeficiency States of animals, chemical etiology are presented.
The Main Characteristics of The Immune Status of Animals Under The Influence of Various Xenobiotics

The negative effect of synthetic pyrethroids, organophosphorus pesticides and fluorine compounds on immunobiological reactivity is manifested by a decrease in the functional state of immunocompetent cells, factors of nonspecific protection and antibody synthesis, leading to the formation of active immunity of low tension. In this case, tokution mainly suppresses the immune system of animals. Actellic pyrethroid and neo-stomatin in a greater degree reduces the activity of T-cells. A similar effect was found in the study of the immune status of cattle under the influence of harmful emissions of aluminum production containing fluoride compounds. Neocidol reduces resistance to various diseases not only in animals but also in humans. Well-known goa-nilu vaccine against colibacteriosis and salmonellosis in young farm animals on the background of acute poisoning with organophosphorus pesticides - ethafoam, Tomatina and actellic loses its protective properties [1-3].

\section{Prevention and correction of immunodeficiency in} animals

Prevention of the negative impact on the immune system of animals, neo-somozan, esfenvalerate, atafona, tokuthion, actellic and neocidol, is based on strict control over their content in various environmental objects. In this case, the maximum residue level (MRL) of these ksenobiotikov should be considered: atafona, 
tokuthion, neocidol $-2,0$; neo-somozan, esfenvalerate $-0.2 \mathrm{mg}$ / $\mathrm{kg}$ of feed, respectively. At the same time, the content of aktellik in animal and poultry feed is potentially dangerous and unacceptable. However, for reliable prevention of negative influence of the specified xenobiotics on immunobiological reactivity of an organism of animals their contents in forages, water and other objects of environment is undesirable. To determine the residual amounts of pesticides and other xenobiotics in the objects of veterinary surveillance and contact media used the chemical-analytical methods based on thin-layer and gas chromatography. Correction of immunological failure in animals under the influence of neosomozan, Poltrona, atafona and tokution by immunomodulation of funds with an established effect on T-system immunity: levamisole, pentoxy, dimephosphone, polioksidonija, etc.

At the same time, a reliable therapeutic effect in cases of poisoning by tatutina and actellic is achieved by parenteral (intramuscular or subcutaneous), within 10 days, a 3-fold introduction of dimephosphone $(250,0 \mathrm{mg} / \mathrm{kg})$ in combination with polyvinylpyrrolidone $(5.0 \mathrm{mg} / \mathrm{kg})$, or single - polyoxidonium in the dose of $5.0 \mathrm{mg} / \mathrm{kg}$. It is necessary to pay attention that these immunomodulatory agents keep immunoreactivity of animals at the high physiological level, promote increase of fertility of females, viability of the born young growth and its resistance to various infections $[4,5]$.

\section{References}

1. Zhulenko VN (2004) Veterinary toxicology. Kolos, Moscow, Russia, p. 384.

2. Melnikov NN (1985) A handbook on pesticides. Chemistry, Moscow, Russia.

3. Roeder John (2008) Veterinary toxicology “Aquarium-Print” p. 416.

4. Salimov Y (2016) The toxicology of modern pyrethroids used in veterinary medicine, prevention and treatment of poisoning of animals. Autoref Doc Diss Samarkand.

5. Khmelnitsky GA (1990) Treatment of animals in case of poisoning (Handbook). Harvest, Kiev, Ukraine, p. 213.

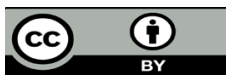

This work is licensed under Creative Commons Attribution 4.0 License

Submission Link: Submit Article

DOI: $10.32474 / C D V S .2019 .02 .000133$

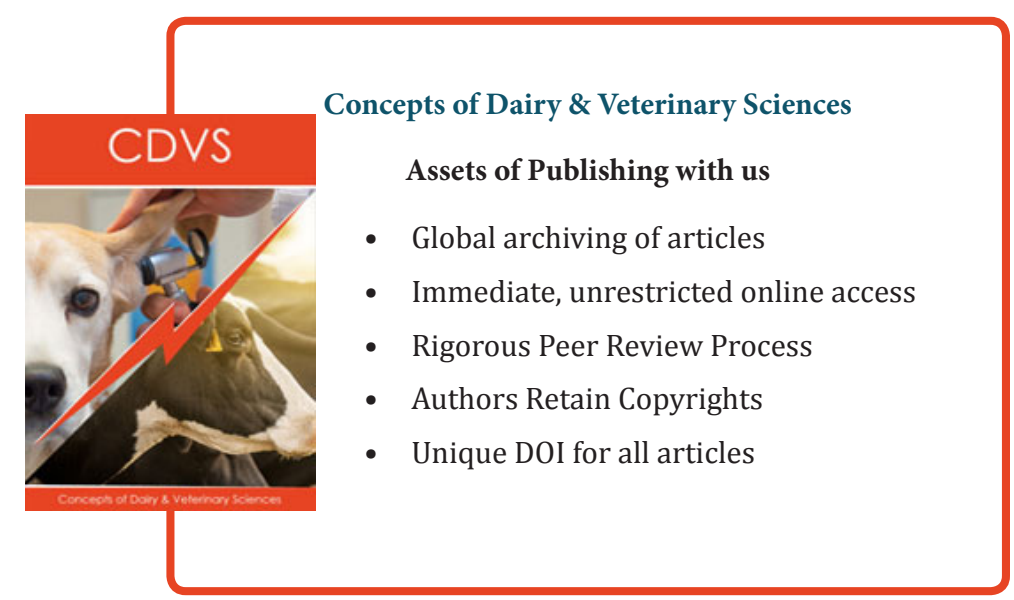

